\title{
Exploring the recycling of bioleaching functional bacteria and sulfur substrate using the sulfur-covered biochar particles
}

\author{
Chuncheng Wu${ }^{1}$, Mengying Jiang ${ }^{1}$, Zhe Ye ${ }^{1}$, Yuchen Cai ${ }^{1}$, Yutao Shen ${ }^{1}$, Haizhen Wang ${ }^{1}$, Qi Lin', \\ Chaofeng Shen ${ }^{1}$, Baolan Hu${ }^{1}$ and Liping Lou ${ }^{1,2^{*}}$ (D)
}

\begin{abstract}
Background: Bioleaching has been attracting attention in the recent years as an emerging sediment heavy metal pollution remediation technology. However, the use of sulfur powder as sulfur substrate causes the problem of "postacidification", and the free bioleaching functional bacteria which are susceptible to environmental impact during reactor operation cannot be used efficiently for multiple rounds. These problems can be solved if the sulfur substrate and the bioleaching functional bacteria can be recycled simultaneously after bioleaching. A new kind of sulfur substrate, the laboratory-made sulfur-covered biochar particles, was used in the bioleaching experiment, compared with sulfur powder and sulfur powder mixed with the surfactant rhamnolipid.
\end{abstract}

Results: The sulfur-covered biochar particles exhibited superior bioleaching performance, including faster acidification rate, $\mathrm{SO}_{4}{ }^{2-}$ production rate and heavy metal bioleaching rate, and higher heavy metal solubilization percentage (Ni 33.76\%; Cu 66.16\%; Zn 65.494\%), which resulted from the acceleration of bioleaching reaction by the bioleaching functional bacteria immobilized on the biochar surface. Otherwise, the sulfur-covered biochar particles could be reused in the second round, and the heavy metal solubilization percentage (Ni 32.84\%, Cu 69.93\%, Zn 67.17\%) was comparable with that of the first round. Nevertheless, the sulfur content became the main limiting factor causing poor bioleaching performance during the third round. Sulfur mixed with the surfactant rhamnolipid did not show significant effect in promoting acidification and heavy metal solubilization due to high levels of organic matter and the impact of the low pH value.

Conclusion: The research indicated the laboratory-made sulfur-covered biochar particles could realize the dual immobilization of the bioleaching functional bacteria and the sulfur substrate to support their recycling and reuse in the second bioleaching round. In the future research, the way to maintain the reuse of the sulfur-covered biochar particles for more rounds will be explored.

Keywords: Sediment, Bioleaching, Recycle, Sulfur-covered biochar particles, Dual immobilization

\section{Background}

In order to ensure the normal traffic of waterways and the safety of water quality, regular dredging work is inevitable. However, the heavy metal content of the dredged

\footnotetext{
*Correspondence: loulp@zju.edu.cn

${ }^{1}$ Department of Environmental Engineering, Zhejiang University,

Hangzhou 310029, Zhejiang, People's Republic of China

Full list of author information is available at the end of the article
}

sediment often exceeds the environmental quality standard due to human activities. The heavy metal pollution remediation of the sediment is urgent. Compared to chemical methods, such as the direct use of mineral acids or chelating agents [1-3], bioleaching as an emerging sediment heavy metal pollution remediation technology has the advantages of environmentally friendly, energy-saving and low cost [4]. Bioleaching is a biological
Springer Open (c) The Author(s) 2020. This article is licensed under a Creative Commons Attribution 4.0 International License, which permits use, sharing, adaptation, distribution and reproduction in any medium or format, as long as you give appropriate credit to the original author(s) and the source, provide a link to the Creative Commons licence, and indicate if changes were made. The images or other third party material in this article are included in the article's Creative Commons licence, unless indicated otherwise in a credit line to the material. If material is not included in the article's Creative Commons licence and your intended use is not permitted by statutory regulation or exceeds the permitted use, you will need to obtain permission directly from the copyright holder. To view a copy of this licence, visit http://creativeco mmons.org/licenses/by/4.0/. 
remediation technology utilizing acidophilus autotrophic bacteria including At. ferrooxidans, At. thiooxidans, Thiobacillus thioparus, Leptospirillum ferrooxidans, etc., to perform bioleaching reaction [5]. These bioleaching functional bacteria can oxidize sulfur, reduced sulfur compound or/and ferrous ions to produce sulfuric acid and ferric ions, which have strong leaching ability [6] and can solubilize metals in their reduced forms and those associated with acid-soluble ores [7].

However, there are some problems in bioleaching technology that hinder its development in engineering applications.

On the one hand, the most common used sulfur substrate in the bioleaching is sulfur powder, because it has a large specific surface area and can facilitate the adsorption and the growth of bacteria on the substrate to enhance the oxidation rate of sulfur [8]. However, the sulfur powder has high hydrophobicity and it is difficult to disperse in the liquid phase. Only $40-60 \%$ of the sulfur powder can be utilized in the bioleaching process in general [9]. The sulfur powder remaining in the sediment increases the operational cost and can cause "post-acidification" problem, which complicates the subsequent disposal of the sediment. The general solution is to add supplementary surfactant or to replace the sulfur powder with bio-sulfur [10-12]. Nevertheless, the addition of the industrial chemical surfactant might influence the growth of the bacteria and can cause secondary pollution. The bio-surfactant costs high and is not suitable for large-scale engineering applications; while the bio-sulfur has the disadvantages of limited sources, easy formation of colloidal solution.

On the other hand, in the microbial engineering application, the free bacteria in the reactor often underperform due to not being well colonized and being susceptible to environmental fluctuations [13]. This problem can be solved by utilizing the microorganisms immobilization technology. The technology immobilized specific microorganisms on a carrier, restricting or positioning them in a certain area, so the microorganisms can maintain a high density and high biological activity, and can proliferate quickly [14]. This technology has the advantages of less microorganisms loss, strong toxicity resistance, and reusable microorganisms $[15,16]$. The choice of the carrier material is crucial to this technology. An appropriate carrier can not only increase the number and the activity of the microorganisms, but also achieve efficient recycle of the microorganisms.

These two problems can be solved at the same time if a suitable carrier can be utilized to immobilize sulfur substrate and bioleaching functional bacteria, because the residual sulfur substrate and the active bioleaching bacteria can be reused multiple times by recycling the carrier.
In order to overcome the "post-acidification" problem and simplify the steps of the repetitive addition of bioleaching inoculum during the operation of the bioleaching sequencing batch reactor, the research selected bamboo biochar as the carrier to produce the recyclable sulfur-covered biochar particles by solidifying melted elemental sulfur on the surface of the bamboo biochar. The research investigated the bioleaching effect of the sulfur-covered biochar particles compared with the sulfur powder and the sulfur powder mixed with the surfactant rhamnolipid. The research also explored the potential and the mechanism of the immobilization of the bioleaching functional bacteria on the sulfur-covered biochar particles and their recycling use. The research also explored the change in the structure of microflora during the bioleaching process using the integrated highthroughput absolute abundance quantification (iHAAQ) technology [17].

\section{Materials and methods \\ Properties of sediment}

The sediment sample selected in this study was from Puti Lake, Jiaxing, Zhejiang Province, China (E 120.73, $\mathrm{N} 30.95^{\circ}$ ). The grab dredger was used to collect the sediment sample from the bottom layer within $0-30 \mathrm{~cm}$. The coarse suspended matter was removed using a 20 mesh screen. The physical and chemical properties of the sediment were measured as follows: $\mathrm{pH}$ 7.29, Eh $-159.83 \mathrm{mv}$, total nitrogen $3.04 \mathrm{~g} / \mathrm{kg}$, total carbon $31.11 \mathrm{~g} / \mathrm{kg}$, acid volatile sulfur (AVS) $2.20 \mathrm{mg} / \mathrm{kg}$ and total solid $22.10 \%$. The concentrations of various heavy metals were as follows: $\mathrm{Ni} 84 \mathrm{mg} / \mathrm{kg}, \mathrm{Cu} 284 \mathrm{mg} / \mathrm{kg}, \mathrm{Zn}$ $394 \mathrm{mg} / \mathrm{kg}$. The heavy metal concentrations of the sediment were analyzed using the method mentioned in "Analysis of heavy metal contents" after the acid digestion of the sediment.

\section{Properties of sulfur substrate}

The sulfur substrate used in the research included sulfur-covered biochar particles, sulfur powder and sulfur powder mixed with surfactant rhamnolipid (see Table 1 for details). The sulfur-covered biochar particles were prepared by the laboratory: the bamboo biochar was purchased from Lin'an Yaoshi Biochar Industry Co., Ltd. Bamboo sawdust was anaerobic-burned at $500{ }^{\circ} \mathrm{C}$ for $8 \mathrm{~h}$, and the bamboo biochar particles were sieved with a mortar mill to obtain the particle size required for the research. After that, the bamboo biochar particles were washed three times with distilled water, and dried at $105{ }^{\circ} \mathrm{C}$ for $6 \mathrm{~h}$. The surface area of the prepared bamboo biochar particles was $332.10 \mathrm{~m}^{2} / \mathrm{g}$. The main components included C (56.05\%), H (1.32\%), N (0.23\%), O (2.62\%), ash (39.78\%), P (0.29\%) and $\mathrm{Na}(0.01 \%)$. 
Table 1 The properties of the different sulfur substrates

\begin{tabular}{|c|c|c|c|c|c|}
\hline Code & Sulfur substrate & Sulfur content & Particle size & Source & Note \\
\hline S & Sulfur powder & $\geq 99.5 \%$ & $200-300 \mu \mathrm{m}$ & $\begin{array}{l}\text { Shijiazhuang Jiyanzheng- } \\
\text { nong corporation }\end{array}$ & - \\
\hline SC & Sulfur-covered biochar particles & $70 \%$ & $\begin{array}{l}\text { Irregular particles } \\
\text { with size of about } \\
5 \mathrm{~mm}\end{array}$ & Prepared by the laboratory & $\begin{array}{l}\text { Prepared by solidifying melted } \\
\text { elemental sulfur on the surface of } \\
\text { the bamboo biochar }\end{array}$ \\
\hline $\mathrm{R}$ & $\begin{array}{l}\text { Sulfur powder mixed with rham- } \\
\text { nolipid }\end{array}$ & $\geq 99.5 \%$ & $200-300 \mu m$ & VICTEX corporation & $\begin{array}{l}\text { Rhamnolipid surfactant is secreted } \\
\text { by Pseudomonas. The added } \\
\text { concentration in the research was } \\
0.3 \mathrm{~g} / \mathrm{L}[10]\end{array}$ \\
\hline C & None & - & - & - & $\begin{array}{l}\text { Control check group, no sulfur } \\
\text { substrate added }\end{array}$ \\
\hline $\mathrm{N}$ & None & - & - & - & $\begin{array}{l}\text { Sterilization treatment group, added } \\
200 \mathrm{mg} / \mathrm{L} \mathrm{NaN}_{3}\end{array}$ \\
\hline
\end{tabular}

And the sulfur-covered biochar particles were produced by solidifying melted elemental sulfur on the surface of the bamboo biochar at $120{ }^{\circ} \mathrm{C}$. After cooling down, the weight of the attached melted sulfur on the bamboo biochar particles was measured in order to control the same sulfur content in each experiment group.

\section{Preparation of the sludge-enriched inoculum}

The inoculum used in this experiment was obtained from the acclimation of the sludge indigenous bacterium in Hangzhou Qige Wastewater Treatment Plant. And the preparation methods were consistent with the previous research [18].

\section{Bioleaching experiment}

Three experiment groups were set up according to the sulfur substrate added: sulfur powder group (experimental code: S-A), sulfur-covered biochar particles group (experimental code: SC-A), sulfur powder mixed with rhamnolipid (experimental code: R-A). The bioleaching experiments were conducted in a $250-\mathrm{mL}$ conical flask containing $2.5 \mathrm{~g}$ dry weight of sediment, $150 \mathrm{~mL}$ of distilled water (the sediment concentration was decided by pre-experiment), $3 \mathrm{~g} / \mathrm{L}$ of sulfur substrate (calculated by sulfur content) and $3 \mathrm{~mL}$ of sludge-enriched inoculum (-A represented the addition of the inoculum). Control groups without sulfur substrate and sterilization groups without sulfur substrate but with $200 \mathrm{mg} / \mathrm{L} \mathrm{NaN}_{3}$ were set at the same time (the experimental code: $\mathrm{C} / \mathrm{N}$ ).

The conical flasks were placed in a shaking incubator at $28^{\circ} \mathrm{C}$ and $180 \mathrm{r} / \mathrm{min}$. Each treatment consisted of nine parallel groups, three of which were used to measure $\mathrm{pH}$, concentration of $\mathrm{SO}_{4}{ }^{2-}$ and heavy metal on a daily basis. Distilled water was added daily to compensate for the loss of vaporization. The supernatant was withdrawn daily and the concentration of $\mathrm{SO}_{4}{ }^{2-}$ and heavy metals was analyzed. The other six parallel groups were tested for microbiological analysis on Day 4 and Day 9 , respectively.

When it came to Day 9, the Tessier sequential extraction method was employed to determine the content of different heavy metal forms in the solid phase after bioleaching [19]. The forms of heavy metals are represented as follows in Fig. 2: Res=residual state; $\mathrm{Org}=$ organic state; $\mathrm{Fe}-\mathrm{Mn}=$ iron-manganese oxidation state; $\mathrm{Car}=$ carbonate-bound state; $\mathrm{Exc}=$ exchangeable state.

After the first round, the sulfur-covered biochar particles of the SC-A group were recovered by filtration and washed with sterile physiological saline 3 times before being used for the second round of bioleaching. The experimental conditions of the second round were the same as those of the first round, but no bioleaching functional bacteria or sulfur substrate were added in all experimental groups. The third round of bioleaching experiment was carried out by the same experimental method. The $\mathrm{pH}$ value, concentration of $\mathrm{SO}_{4}{ }^{2-}$ and heavy metals of the samples were measured every day to investigate the bioleaching effect of the sulfur-covered biochar particles in the multiple recycling rounds.

\section{Analysis method}

The $\mathrm{pH}$ value was measured using $\mathrm{pH}$ meter (PB-10) using the National Standard Method HJ 962-2018. The concentration of $\mathrm{SO}_{4}{ }^{2-}$ was detected by ion chromatography (ICS-1100); total nitrogen, total carbon, and total phosphorus of the sediment sample were determined using an elemental analyzer (Elementar vario MAX CNS). The specific surface area of the biochar samples were measured using the American Tristar III3020 automatic specific surface area. The BET 
(Brunauer-Emmett-Teller) equation was used to calculate the surface area of the bamboo biochar particles [20]. The EA110 elemental analyzer was utilized to determine the percentages of elements $\mathrm{C}, \mathrm{H}$, and $\mathrm{N}$ in the biochar samples [21]. Field emission scanning electron microscope (FEI SIRION-100) was utilized to observe the surface structure and the colonization of the microorganisms on the sulfur-covered biochar particles.

\section{Analysis of heavy metal content}

The heavy metal concentration of the sample was detected by an inductively coupled plasma mass spectrometer (ICP-MS) (PQMS 10-5000S-AR091). The limit of detection (LOD) of the ICP-MS is $1 \mathrm{ppb}$, the accuracy was $<5 \%$, and the relative standard deviation (RSD) was $<5 \%$. To control the analytical quality of the analytical procedure, a certified reference material (GBW-07405) was applied and analyzed following the same procedure. The recoveries of $\mathrm{Ni}, \mathrm{Cu}$ and $\mathrm{Zn}$ were in the range of $74.3-113.3 \%(n=3)$. The recoveries of heavy metals during the sequential extraction process were in the ranges of $79.08-117.92 \%, 76.16-107.94 \%$ and $74.93-113.62 \%$, respectively. The method to calculate the recoveries of heavy metal during the sequential extraction process was written in Additional file 1. These results indicated that our methods were reliable and precise enough for the purposes of this study.

\section{Microbiological analysis}

Using the iHAAQ methodology proposed by Lou et al., the qPCR analyses were performed to quantify the specific genes of the extracted DNA with three replicates using a StepOnePlus TM Real-Time PCR System instrument (Applied Biosystems, Foster City, CA, USA). The high-throughput sequencing was performed by using Illumina Miseq platform following standard protocols. The quality control of raw sequencing reads was performed using QIIME software (version 1.7.0). The absolute abundance of each genus level of the top 30 most abundant microorganisms in the sediment was calculated by multiplying the total abundance of bacteria (the copy number of the $16 \mathrm{~S}$ rRNA gene in the V4 region measured by qPCR) and the corresponding relative abundance obtained by high-throughput sequencing [17].

\section{Data analysis}

The mathematical calculations involved in the study were done using Matlab 2017 software. The chart making and function curve fitting involved in the research were completed using Origin 8.0 software. The correlation analysis was performed using SPSS V22.0 software.

Heavy metal bioleaching curves were fitted using logistic equations [22]:

$$
M=M_{\text {limit }}-B /\left[1+\left(\frac{t}{x}\right)^{p}\right] .
$$

In the formula, $M$ is the concentration of heavy metal $(\mathrm{mg} / \mathrm{kg})$ in the liquid phase; $M_{\text {limit }}$ is the upper limit bioleaching concentration of heavy metal $(\mathrm{mg} / \mathrm{kg}) ; t$ is the bioleaching time; $x, B$, and $p$ are constants.

We assumed that when $M=95 \% M_{\text {limit }}$ the bioleaching is finished. Then based on Eq. (1), $T_{95 \%}$ could be calculated using Eq. (2):

$$
T_{95 \%}=x * \sqrt[p]{B /\left(5 \% * M_{\text {limit }}-1\right)} .
$$

Using Eq. (1) to further determine the derivative of the time $t$ and the bioleaching time $T_{V_{\max }}$ (day), at which the maximum bioleaching rate $V_{\max }(\mathrm{mg} / \mathrm{kg} /$ day $)$ is reached, can be obtained.

\section{Results \\ Bioleaching performance of sulfur-covered biochar particles}

There was no significant difference in acidification rate within the experiment groups after the addition of the sludge-enriched inoculum. The SC-A group achieved the fastest acidification rate ( $\mathrm{pH}$ reached 2.35 on the Day 5) and the lowest $\mathrm{pH}$ value ( $\mathrm{pH}$ reached 1.80 on the Day 9) (Fig. 1). Although the specific surface area of the sulfur powder was much larger than that of the sulfur-covered biochar particles, the acidification rate of the S-A group was slightly slower than that in the SC-A group $(\mathrm{pH}$ reached 2.44 on the Day 6). In the R-A group, rhamnolipid was added as a surfactant to more easily disperse the sulfur powder in the liquid phase, but its acidification rate was the slowest ( $\mathrm{pH}$ reached 2.36 on the Day 8). In order to investigate the acidification performance of the

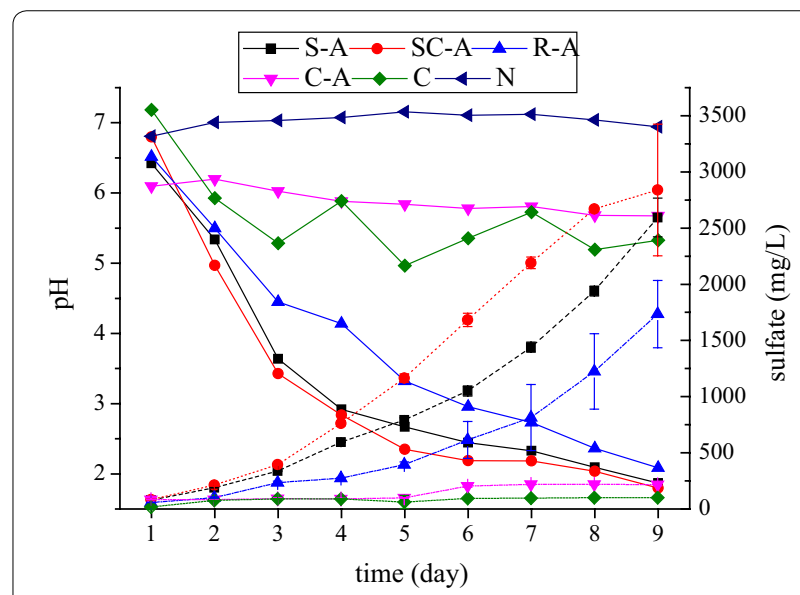

Fig. 1 Acidification (solid line) and $\mathrm{SO}_{4}{ }^{2-}$ production (dotted line) during bioleaching 
indigenous microorganisms in the sediment, the $C$ group and the $\mathrm{N}$ group were set. When no sulfur substrate was added (the $\mathrm{C}$ group), the presence of indigenous microorganisms in the sediment also kept the system acidic $(\mathrm{pH}$ was about 5.5), while the $\mathrm{pH}$ of the $\mathrm{N}$ group remained at around 7.

The shorter the time bioleaching finished, the faster the total bioleaching rate. The SC-A group with the fastest acidification rate and the shortest the bioleaching time had the fastest total bioleaching rate (Table 2), and it also reached the highest heavy metal solubilization $(\mathrm{Ni}$ 33.76\%; $\mathrm{Cu}$ 66.16\%; Zn 65.49\%). While the total bioleaching rate of the R-A group was slower than those of the $\mathrm{S}$-A group and the SC-A group, these experiment groups with inoculum added all reached almost the same heavy metal solubilization at the end of the bioleaching experiment (Fig. 2).

For the three heavy metals studied, the heavy metal solubilization percentage was in decreasing order: $\mathrm{Cu}>\mathrm{Zn}>\mathrm{Ni}$ (Additional file 1: Fig. S1), $\mathrm{Zn}$ and $\mathrm{Cu}$ were likely to be leached while $\mathrm{Ni}$ was least likely to be leached, which was similar to previous studies [23, 24].
The logistic formula (1) can fit the heavy metal bioleaching curve very well (see Table 2 for detailed parameters of curve fitting). Formula (2) can be used to calculate the time required for each sulfur substrate to reach the bioleaching end point. Formula (1) can be used to obtain $V_{\max }(\mathrm{mg} / \mathrm{kg} /$ day $)$ and the time it appears $T_{V \max }$ (day).

According to Table 2, the $V_{\max }$ was related to the heavy metal leached. The $V_{\max }$ of the three heavy metals in the increasing order was $\mathrm{Zn}>\mathrm{Cu}>\mathrm{Ni}$. Chen et al. [37] found that the higher the initial heavy metals contend in the sediment, the faster the $V_{\max }$ which was consistent with our result.

The SC-A group had the fastest acidification rate, $\mathrm{SO}_{4}{ }^{2-}$ production rate, total bioleaching rate, the largest $V_{\max }$ and the corresponding shortest $T_{V_{\max }}$, and it also reached the highest heavy metal solubilization. In addition, the sulfur substrate could be reused when the sulfur-covered biochar particles were recycled. All of these indicated that sulfur-covered biochar particles had superior bioleaching ability and the potential for recycling.

Table 2 Parameters of heavy metal curve fitting when different sulfur substrates are used

\begin{tabular}{|c|c|c|c|c|c|c|c|c|c|}
\hline & Code & $M_{\text {limit }}$ & $x$ & $p$ & $B$ & $T_{V_{\max }}$ (day) & $V_{\max }(\mathrm{mg} / \mathrm{kg} /$ day $)$ & $T_{95 \%}$ (day) & $R^{2}$ \\
\hline \multirow[t]{3}{*}{$\mathrm{Ni}$} & S-A & 30.06 & 3.073 & 2.501 & 32.14 & 2.188 & 7.708 & 10.25 & 0.9618 \\
\hline & SC-A & 29.87 & 2.939 & 2.772 & 31.41 & 2.238 & 8.461 & 8.675 & 0.9755 \\
\hline & R-A & 39.62 & 5.592 & 1.897 & 41.45 & 3.197 & 4.698 & 26.99 & 0.9809 \\
\hline \multirow[t]{3}{*}{$\mathrm{Cu}$} & S-A & 193.5 & 3.850 & 4.890 & 197.2 & 3.537 & 65.31 & 7.06 & 0.9939 \\
\hline & SC-A & 195.2 & 3.627 & 4.351 & 200.4 & 3.271 & 73.87 & 6.27 & 0.9882 \\
\hline & R-A & 214.5 & 6.020 & 5.485 & 215.0 & 5.692 & 50.59 & 10.30 & 0.9974 \\
\hline \multirow[t]{3}{*}{$\mathrm{Zn}$} & S-A & 237.8 & 2.952 & 4.117 & 245.3 & 2.616 & 90.78 & 6.08 & 0.9800 \\
\hline & SC-A & 247.2 & 2.833 & 4.455 & 252.3 & 2.555 & 104.35 & 5.50 & 0.9882 \\
\hline & R-A & 298.6 & 5.088 & 3.185 & 303.7 & 4.147 & 52.53 & 12.92 & 0.9829 \\
\hline
\end{tabular}

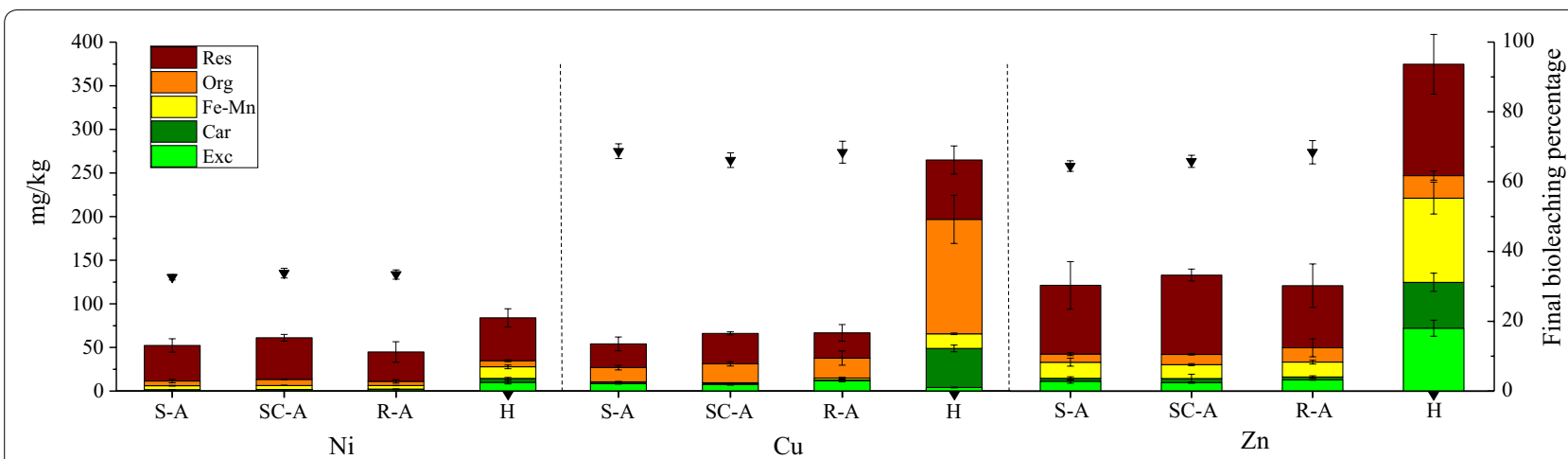

Fig. 2 Solubilizations of $\mathrm{Ni}, \mathrm{Cu}, \mathrm{Zn}$, and distribution of heavy metal forms before and after bioleaching. $\mathrm{H}$ represents sediment without bioleaching treatment. The triangle represents the solubilization of each group 


\section{Bioleaching functional bacteria immobilization effect of sulfur-covered biochar particles}

In order to test the bioleaching functional bacteria immobilization effect of sulfur-covered biochar particles, samples were collected for microbiological analysis in the middle of the experiment (Day 4) and the end of the experiment (Day 9). The integrated high-throughput absolute abundance quantification (iHAAQ) technology was used to investigate the changes in the flora structure and abundance during bioleaching (Fig. 3). The result showed that the absolute abundance of top 30 microorganisms in the $\mathrm{SC}$-A group was less than the S-A group in the middle of the experiment. Among the dominant microorganisms associated with bioleaching, only Acidithiobacillus and Sulfuritalea were more abundant in the SC-A group. However, the situation reversed at the end of the experiment, the sulfur-covered biochar particles of the SC-A group enriched higher abundance of the top 30 microorganisms, regardless of whether they were related to bioleaching.

At the same time, we performed scanning electron microscope observations of the sulfur-covered biochar particles recycled from the first round of bioleaching. The observation showed that large amount of rod-shaped microorganisms was immobilized on the surface of the sulfur-covered biochar particles, and the sulfur layer on the surface became rough and complicated due to metabolism of the bioleaching bacteria (Fig. 4).

\section{Reuse of recoverable sulfur-covered biochar particles in bioleaching}

In order to investigate the feasibility of reusing the sulfur-covered biochar particles in multiple bioleaching rounds, the sulfur-covered biochar particles used in the first bioleaching round were recycled to be reused in the second and the third round of bioleaching, meanwhile no more sulfur substrate and sludge-enriched inoculum were added. The results showed that both the first round and the second round could reach $\mathrm{pH}<2.5$ when it came to Day 9, but the $\mathrm{pH}$ value of the third bioleaching round only reached 3.5 when the experiment came to an end. Although the final pH values of the first round and the second round were very close, the $\mathrm{SO}_{4}{ }^{2-}$ production of the second round was much lower than the first round, and the $\mathrm{SO}_{4}{ }^{2-}$ production rate of the third round stayed flat. At the end of the second bioleaching round, the heavy metals solubilization was $\mathrm{Ni} 32.84 \%, \mathrm{Cu} 69.93 \%$ and $\mathrm{Zn} 67.17 \%$, while only $\mathrm{Ni} 20.09 \%, \mathrm{Cu} 10.28 \%$ and $\mathrm{Zn} 37.20 \%$ in the third round. Therefore, the recycled sulfur-covered biochar particles could support the second round of bioleaching, and the heavy metals solubilization was satisfied. When it came to an end of the third bioleaching round, only $20.25 \%$ elemental sulfur still remained on the biochar particles.

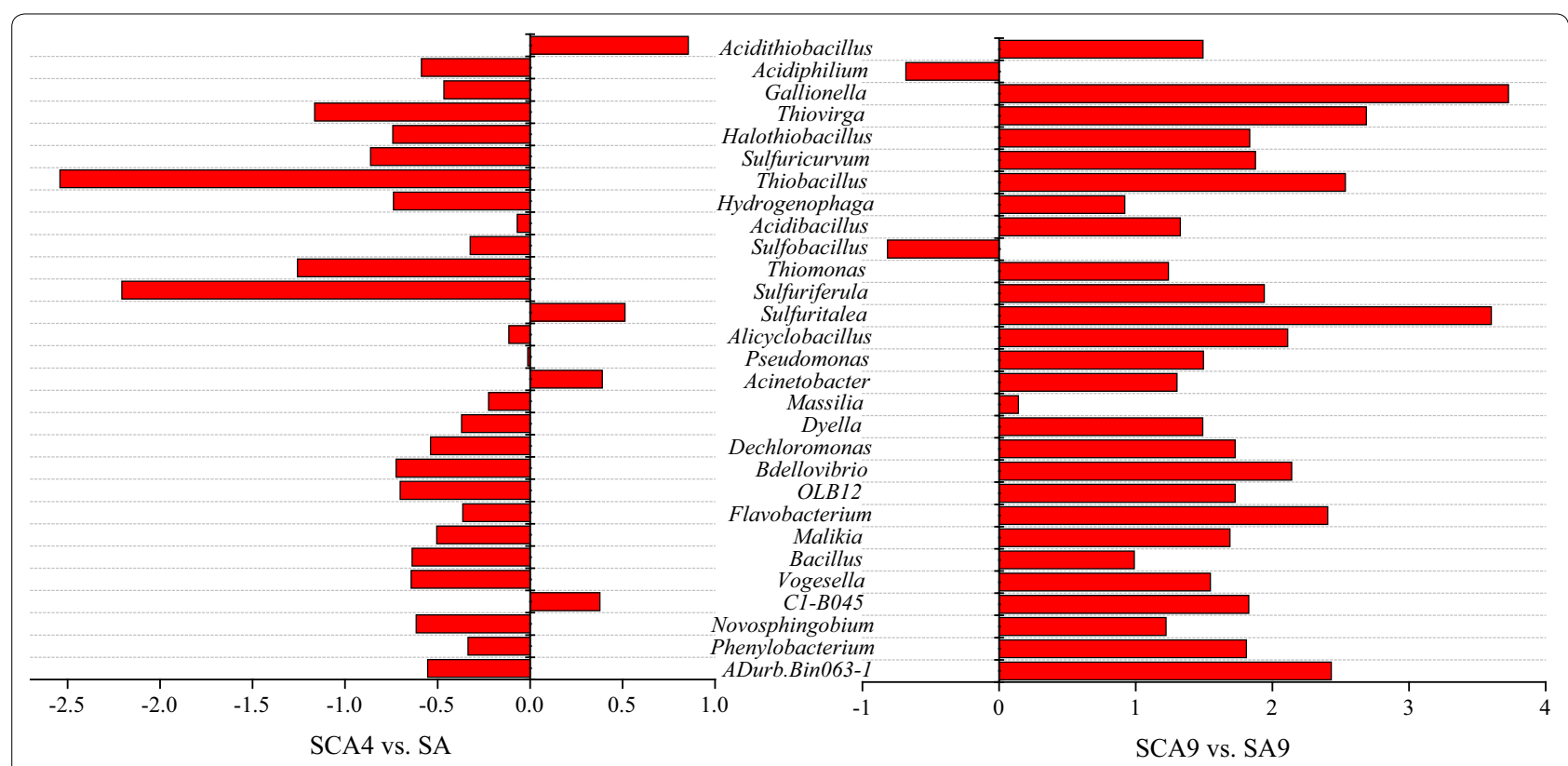

Fig. 3 The fold change of the absolute abundance of the SC-A group vs. the S-A group. The numbers 4 and 9 represent the sample of the Day 4 and the Day 9 


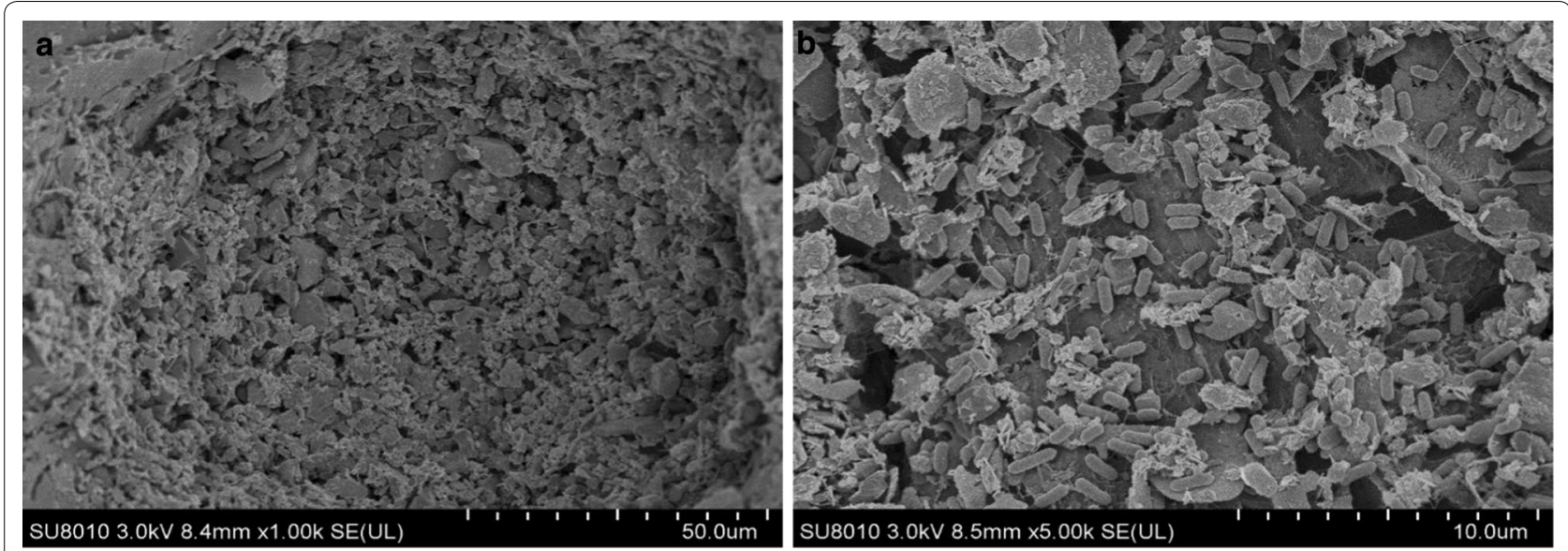

Fig. 4 The scanning electron microscope result of the SC-A group on the Day 9. The magnifications of $\mathbf{a}$ and $\mathbf{b}$ were $(\times 1000)$ and $(\times 5000)$, respectively

\section{Discussion}

\section{Acidification and oxidation of sulfur}

It is generally accepted that the solubilization of the acid-soluble metal sulfides is caused by the attack of the proton (the "polysulfide pathway") [25, 26], while the acid-insoluble metal sulfides are dissolved by the combination of oxidative attack and proton attack (the "thiosulfate pathway") [27]. Therefore, we can investigate the acidification rate and the production of $\mathrm{SO}_{4}{ }^{2-}$ to judge the bioleaching of heavy metals from the side, and the result showed that the faster the $\mathrm{pH}$ declined, the faster the $\mathrm{SO}_{4}{ }^{2-}$ was produced, indicating that the acidification of the system was caused by the oxidation of sulfur to produce $\mathrm{H}_{2} \mathrm{SO}_{4}$.

Sulfur powder is highly hydrophobic and difficult to disperse in the liquid phase, but it has a large specific surface area, so it is more prone to adsorb microorganisms and promote their growth, and its production rate of $\mathrm{SO}_{4}{ }^{2-}$ tends to be fast [9]. However, the acidification rate and $\mathrm{SO}_{4}{ }^{2-}$ production rate of the $\mathrm{S}$-A group were slower than the SC-A group. Many studies have reported that the biochar is redox-active due to its quinone group and aromatic structure [28-30]. We performed Fourier transform infrared spectroscopy on the biochar particles used in the experiment. The results showed that the infrared absorption peak appeared at $1610 \mathrm{~cm}^{-1}$, indicating the existence of quinone structure (Additional file 1: Fig S2). The electron transfer in the process of microbial oxidation of elemental sulfur could be enhanced, resulting from the transformation of the oxidation and reduction states of quinone structure. Therefore, the comparable acidification rate of sulfur-covered biochar particles and sulfur powder may result from the acceleration of sulfur oxidation rate, especially when microbial oxidation was happening at the same time.
Rhamnolipid is a biological surfactant commonly produced by strains of the genus Pseudomonas. The release of this biological surfactant promotes emulsification of the hydrocarbon phase, rendering such lipophilic molecules available to the metabolic pathways of microorganisms [31]. However, the R-A group did not show a significant effect in promoting the bioleaching acidification. This could be caused by the organic matters the rhamnolipid contained, which inhibit the autotrophic metabolism of indigenous sulfur-oxidizing bacteria. The growth of bioleaching functional strains could be inhibited by organic compounds such as pyruvic acid, citric acid, oxaloacetic acid, and glucose [32-35].

\section{Heavy metal bioleaching performance}

A large proportion of $\mathrm{Cu}$ in the sediment sample existed in the organic state (49.14\%), and $\mathrm{Zn}$ mostly existed in exchangeable, carbonate-bound, and iron-manganese oxidation states $(57.30 \%)$. In this case, $\mathrm{Zn}$ and $\mathrm{Cu}$ had high bioleaching levels in the experiment. The research found that the residual state was the most difficult form to be leached [36,37], this is because that heavy metals in the residual form bound to a resistant crystal structure rarely contact sulfuric acid [38]. Therefore, the amount of the residual form determined the upper limit of the bioleaching of heavy metals and Ni mostly existing in the residual form was the most difficult metal to be leached.

The kind of sulfur substrate affected the acidification rate, which in turn affected the total bioleaching rate, and the distribution of the initial form of the heavy metal determined the level of heavy metal solubilization in bioleaching. This explained why three experiment groups had different total bioleaching rate, but they all reached similar heavy metal solubilization and the distribution of heavy metal form in the sediment after bioleaching. 
Extraction of metals by anionic surfactant rhamnolipid through solubilization has been known and previously applied with effective results [39-41]. However, the R-A group did not show significant effect in promoting heavy metal solubilization in the research. This may be because that as the $\mathrm{pH}$ in the bioleaching system declined, the water solubility, surface tension and the number of heavy metal binding sites of the rhamnolipid continued to decrease $[40,42]$. Otherwise, the complicated competitive ions and ligands in the sediment system were important factors affecting the adsorption and solubilization of heavy metals by rhamnolipid.

\section{Immobilization function of biochar}

The microbiological analysis and the scanning electron microscope result proved that the sulfur-covered biochar particles could enrich and immobilize bioleaching functional bacteria from the sediment.

The reason why sulfur-covered biochar particles could immobilize large amount of bacteria may be related to its carrier bamboo biochar. Biochar contains a series of nutrients (such as $\mathrm{K}^{+}, \mathrm{Mg}^{2+}, \mathrm{Na}^{+}, \mathrm{N}$, P, etc.), and because of its negative surface charge, it can also absorb salt ions in the surrounding environment to provide nutrients for microorganisms [43]. The adsorption of heavy metals leached during the bioleaching process on the biochar could reduce heavy metals bioavailability, which alleviated their toxicity to the microorganisms [44, 45]. Besides, the large specific surface area and the high pore volume of the biochar can provide safe and suitable microenvironment for microorganisms to grow [46]. Otherwise, the sulfur melted on the surface of the bamboo biochar particles provided the elemental sulfur as sulfur substrate while also expanding the reaction area to a certain extent. Therefore, compared with sulfur powder, the addition of sulfur-covered biochar particles had a stronger promotion effect on the growth of sulfur-oxidizing autotrophs.

\section{Potential reuse of sulfur-covered biochar particles}

The recycled sulfur-covered biochar particles had satisfied bioleaching performance in the second round of bioleaching, but their sulfur content became the main limiting factor in the third or more rounds. Similar conclusion could also be obtained by combining the distribution figure of the elemental sulfur in different rounds (Fig. 5). In addition, we found that there was still much elemental sulfur that was not converted to $\mathrm{SO}_{4}{ }^{2-}$ but was wasted or converted to other sulfur compounds remained in the sediment, which indicated the complexity of the sulfur-oxidizing bacteria metabolism during bioleaching process in the sediment.

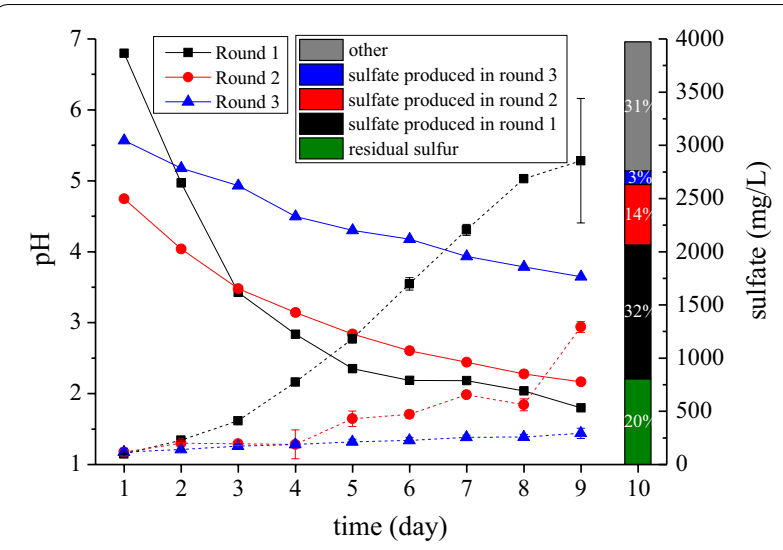

Fig. 5 Acidification, $\mathrm{SO}_{4}{ }^{2-}$ production and the distribution of the elemental sulfur in the three bioleaching rounds (acidification curve: solid line; $\mathrm{SO}_{4}{ }^{2-}$ concentration: dotted line)

The sulfur residue that remained on the biochar particles was different from sulfur powder; it was immobilized on the biochar particles and could be recycled efficiently, which avoided the problem of "post-acidification" and secondary pollution. No inoculum addition during the second bioleaching round indicated that the use of the sulfur-covered biochar particles could also simplify the operational step of the inoculum addition. Nevertheless, the sulfur-covered biochar particles could only maintain two rounds of bioleaching, and the third and more rounds of bioleaching were limited due to insufficient sulfur substrate. In the future research, it is considered to add a small amount of sulfur powder or supplement new sulfur-covered biochar particles to maintain a necessary sulfur content in the subsequent rounds of bioleaching, so as to achieve the reuse of the sulfur-covered biochar particles. In the current chemical fertilizer industrial production, the production operation of sulfur-covered urea particles is realized, which manifested that the industrial production of the sulfur-covered biochar particles is also practicable.

\section{Conclusion}

The result showed that the sulfur-covered biochar particles had the fastest acidification rate, $\mathrm{SO}_{4}{ }^{2-}$ production rate and heavy metal bioleaching rate, and the highest heavy metal solubilization, which resulted from the acceleration of bioleaching reaction by the bioleaching functional bacteria immobilized on the biochar surface. Meanwhile, the dual immobilization of the bioleaching functional bacteria and the sulfur layer on the sulfur-covered biochar particles realized their recycling and their reuse in the second bioleaching round. In the 
future research, a small amount of sulfur powder or new sulfur-covered biochar particles will be supplemented to achieve more rounds of recycling of the sulfur-covered biochar particles, so as to maintain the reuse of the sulfur-covered biochar particles, to overcome the "post-acidification" problem and simplify the steps of the repetitive addition of bioleaching inoculum during the operation of the bioleaching sequencing batch reactor.

\section{Supplementary information}

Supplementary information accompanies this paper at https://doi. org/10.1186/s12302-020-00344-3.

Additional file 1: Fig. S1. Amount of heavy metal leached from the sediment during the bioleaching process. Fig. S2. Infrared spectrum analysis of bamboo biochar. Fig. S3. Amount of heavy metal leached from the sediment during the second and the third round of bioleaching.

\section{Abbreviations}

S-A: The sulfur powder groups with inoculum added; SC-A: The sulfur-covered biochar particles groups with inoculum added; R-A: The sulfur powder mixed with rhamnolipid groups with inoculum added; $\mathrm{C}$ : The control groups; C-A: The control groups with inoculum added; $\mathrm{N}$ : The $\mathrm{NaN}_{3}$ groups.

\section{Acknowledgements}

The authors acknowledge the National Science and Technology Major Project 2017ZX07206-003 and the National Natural Science Foundation (Nos. 41877463 and 21677123 ) for their financial support for this study.

\begin{abstract}
Authors' contributions
CCW performed all experiments, analyzed the data and was a major contributor to writing the manuscript. LPL was major contributor to supervision, guided the laboratory experiments and contributed to writing the manuscript. MYJ guided the bioleaching experiment and contributed to writing the manuscript. LCH, YCC, YTS helped with the experiment. HZW, QL, CFS, and BLH contributed to supervision and writing the manuscript. All authors read and approved the final manuscript.
\end{abstract}

\section{Funding}

The study was supported financially by the National Science and Technology Major Project 2017ZX07206-003 and the National Natural Science Foundation (Nos. 41877463 and 21677123).

\section{Availability of data and materials}

The datasets used and/or analyzed during the current study are available from the corresponding author on reasonable request.

\section{Ethics approval and consent to participate}

Not applicable.

\section{Consent for publication}

Not applicable.

\section{Competing interests}

The authors declare that they have no competing interests.

\section{Author details}

${ }^{1}$ Department of Environmental Engineering, Zhejiang University, Hangzhou 310029, Zhejiang, People's Republic of China. ${ }^{2}$ Key Laboratory of Water Pollution Control and Environmental Safety of Zhejiang Province, Hangzhou 310020, People's Republic of China.

Received: 2 January 2020 Accepted: 24 April 2020 Published online: 06 May 2020

\section{References}

1. Tsai L, Yu K, Chen S, Kung P (2003) Effect of temperature on removal of heavy metals from contaminated river sediments via bioleaching. Water Res 37:2449-2457

2. Chen SY, Lin JG (2001) Bioleaching of heavy metals from sediment: significance of $\mathrm{pH}$. Chemosphere 44:1093-1102

3. Ito A, Umita T, Aizawa J, Takachi T, Morinaga K (2000) Removal of heavy metals from anaerobically digested sewage sludge by a new chemical method using ferric sulfate. Water Res 34:751-758

4. Zhang W, Gu S (2007) Catalytic effect of activated carbon on bioleaching of low-grade primary copper sulfide ores. Trans Nonferr Met Soc China 17:1123-1127

5. Fonti V, Dell'Anno A, Beolchini F (2016) Does bioleaching represent a biotechnological strategy for remediation of contaminated sediments? Sci Total Environ 563-564:302-319

6. Beolchini F, Fonti V, Dell Anno A, Rocchetti L, Vegliò F (2012) Assessment of biotechnological strategies for the valorization of metal bearing wastes. Waste Manage 32:949-956

7. Akinci G, Guven DE (2011) Bioleaching of heavy metals contaminated sediment by pure and mixed cultures of Acidithiobacillus spp. Desalination 268:221-226

8. Konishi Y, Takasaka Y, Asai S (1994) Kinetics of growth and elemental sulfur oxidation in batch culture of Thiobacillus ferrooxidans. Biotechnol Bioeng 44:667-673

9. Ravishankar BR, Blais JF, Benmoussa H, Tyagi RD (1994) Bioleaching of metals from sewage-sludge-elemental sulfur recovery. J Environ EngAsce 120:462-470

10. Mo CR, Nie J, Hu ZS, Qin LM, Xu P, Deng GL (2014) Effects of rhamnolipids on biological leaching of chromium from tannery sludge. Sci Technol Eng 14:61-64 (In Chinese)

11. Diaz MA, De Ranson IU, Dorta B, Banat IM, Blazquez ML, Gonzalez F et al (2014) Metal removal from contaminated soils through bioleaching with oxidizing bacteria and rhamnolipid biosurfactants. Soil Sediment Contam Int J 24:16-29

12. Tichy R, Janssen A, Grotenhuis J, Lettinga G, Rulkens Wh (1994) Possibilities for using biologically-produced sulfur for cultivation of thiobacilli with respect to bioleaching processes. Bioresour Technol 48:221-227

13. Li H, Jiang CL, Ding DH, Yang Q, Cai TM (2016) Degradation of 2-hydroxy1,4-naphthoquinone by sodium alginate-biochar combined immobilized strains. J Nanjing Agric Univ 39:800-806 (In Chinese)

14. Karel SF, Libicki SB, Robertson CR (1985) The immobilization of whole cells_engineering principles. Chem Eng Sci 40:1321-1354

15. Hu J, Su X, Han H, Shen C, Shi J (2014) Application prospect about bioremediation of polychlorinated biphenyls-contaminated soil with immobilized microorganism technique: a review. Yingyong Shengtai Xuebao 25:1806-1814 (In Chinese)

16. Hale L, Luth M, Crowley D (2015) Biochar characteristics relate to its utility as an alternative soil inoculum carrier to peat and vermiculite. Soil Biol Biochem 81:228-235

17. Lou J, Yang L, Wang H, Wu L, Xu J (2018) Assessing soil bacterial community and dynamics by integrated high-throughput absolute abundance quantification. PeerJ 6:e4514

18. Wu C, Jiang M, Hsieh L, Cai Y, Shen Y, Wang H et al (2020) Feasibility of bioleaching of heavy metals from sediment with indigenous bacteria using agricultural sulfur soil conditioners. Sci Total Environ 703:134812

19. Tessier A, Campbell P, Bisson M (1979) Sequential extraction procedure for the speciation of particulate trace-metals. Anal Chem 51:844-851

20. Chen B, Johnson EJ, Chefetz B et al (2005) Sorption of polar and nonpolar aromatic organic contaminants by plant cuticular materials: role of polarity and accessibility. Environ Sci Technol 39:6138-6146

21. Ennis CJ et al (2012) Biochar: carbon sequestration, land remediation, and impacts on soil microbiology. Crit Rev Environ Sci Technol 42:2311-2364

22. Gan M, Zhou S, Li M, Zhu J, Liu X, Chai L (2015) Bioleaching of multiple heavy metals from contaminated sediment by mesophile consortium. Environ Sci Pollut Res 22:5807-5816

23. Chen SY, Lin JG (2000) Influence of solid content on bioleaching of heavy metals from contaminated sediment by Thiobacillus spp. J Chem Technol Biotechnol 75:649-656 
24. Chang C, Chen S, Klipkhayai P, Chiemchaisri C (2019) Bioleaching of heavy metals from harbor sediment using sulfur-oxidizing microflora acclimated from native sediment and exogenous soil. Environ Sci Pollut Res 26:6818-6828

25. Schippers A, Jorgensen BB (2002) Biogeochemistry of pyrite and iron sulfide oxidation in marine sediments. Geochim Cosmochim Acta 66:85-92

26. Schippers A, Jozsa PG, Sand W (1996) Sulfur chemistry in bacterial leaching of pyrite. Appl Environ Microbiol 62:3424-3431

27. Schippers A, Sand W (1999) Bacterial leaching of metal sulfides proceeds by two indirect mechanisms via thiosulfate or via polysulfides and sulfur. Appl Environ Microbiol 65:319-321

28. Klüpfel L, Keiluweit M, Kleber M, Sander M (2014) Redox properties of plant biomass-derived black carbon (Biochar). Environ Sci Technol 48:5601-5611

29. Chen S, Rotaru A, Shrestha PM, Malvankar NS, Liu F, Fan W et al (2015) Promoting interspecies electron transfer with biochar. Sci Rep 4:5019

30. Kappler A, Wuestner ML, Ruecker A, Harter J, Halama M, Behrens S (2014) Biochar as an electron shuttle between bacteria and Fe(III) minerals. Environ Sci Technol Lett 1:339-344

31. Ki Hisatsuka, Nakahara T, Sano N, Yamada K (1971) Formation of rham nolipid by pseudomonas aeruginosa and its function in hydrocarbon fermentation. Agric Biol Chem 35:686

32. Johnson DB (1995) Selective solid media for isolating and enumerating acidophilic bacteria. J Microbiol Methods 23:205-218

33. Frattini CJ, Leduc LG, Ferroni GD (2000) Strain variability and the effects of organic compounds on the growth of the chemolithotrophic bacterium Thiobacillus ferrooxidans. Antonie Van Leeuwenhoek 77:57-64

34. Gurung A, Chakraborty R (2009) The role of Acidithiobacillus ferrooxidans in alleviating the inhibitory effect of thiosulfate on the growth of acidophilic Acidiphilium species isolated from acid mine drainage samples from Garubathan, India. Can J Microbiol 55:1040-1048

35. Phj A, Jarvis BW, Johnson JL (1980) Heterotrophic bacteria from cultures of autotrophic Thiobacillus ferrooxidans: relationships as studied by means of deoxyribonucleic acid homology. J Bacteriol 143:448-454

36. Liu Y, Zhou M, Zeng G, Wang X, Li X, Fan T et al (2008) Bioleaching of heavy metals from mine tailings by indigenous sulfur-oxidizing bacteria: effects of substrate concentration. Bioresour Technol 99:4124-4129

37. Chen S, Lin J (2004) Bioleaching of heavy metals from contaminated sediment by indigenous sulfur-oxidizing bacteria in an air-lift bioreactor: effects of sulfur concentration. Water Res 38:3205-3214

38. Cong X, Zhu T, Yan JF et al (2017) Effects of bentonite and its modified version on the stabilization of heavy metal contents in the electroplating sludge. J Saf Environ 17:1155-1159 (In Chinese)

39. Venkatesh NM, Vedaraman N (2012) Remediation of soil contaminated with copper using Rhamnolipids produced from Pseudomonas aeruginosa MTCC 2297 using waste frying rice bran oil. Ann Microbiol 62:85-91

40. Juwarkar AA, Nair A, Dubey KV, Singh SK, Devotta S (2007) Biosurfactant technology for remediation of cadmium and lead contaminated soils. Chemosphere 68:1996-2002

41. Mulligan CN, Wang S (2006) Remediation of a heavy metal-contaminated soil by a rhamnolipid foam. Eng Geol 85:75-81

42. Lin F, Besserer GJ, Pitts MJ (1987) Laboratory evaluation of cross-linked polymer and alkaline-polymer-surfactant flood. J Can Pet Technol 26:54-65

43. Joseph S, Graber ER, Chia C, Munroe P, Donne S, Thomas T et al (2013) Shifting paradigms: development of high-efficiency biochar fertilizers based on nano-structures and soluble components. Carbon Manage 4:323-343

44. Seneviratne M, Weerasundara L, Ok YS, Rinklebe J, Vithanage M (2017) Phytotoxicity attenuation in Vigna radiata under heavy metal stress at the presence of biochar and N fixing bacteria. J Environ Manage 186:293-300

45. Qian L, Chen B, Hu D (2013) Effective alleviation of aluminum phytotoxicity by manure-derived biochar. Environ Sci Technol 47:2737-2745

46. Quilliam RS, Glanville HC, Wade SC, Jones DL (2013) Life in the 'charosphere'-does biochar in agricultural soil provide a significant habitat for microorganisms? Soil Biol Biochem 65:287-293

\section{Publisher's Note}

Springer Nature remains neutral with regard to jurisdictional claims in published maps and institutional affiliations.

\section{Submit your manuscript to a SpringerOpen ${ }^{\circ}$ journal and benefit from:}

- Convenient online submission

- Rigorous peer review

- Open access: articles freely available online

- High visibility within the field

- Retaining the copyright to your article

Submit your next manuscript at springeropen.com 